\title{
Influence of Annealing and Normalizing Treatment to The Hardness and Microstructure of Friction Stir Welding Al-5052
}

\author{
Bibit Sugito $^{1 *}$ Agus Dwi Anggono ${ }^{1}$, Aditya Qomarudin ${ }^{1}$ \\ ${ }^{1}$ Faculty of Engineering, Universitas Muhammadiyah Surakarta. \\ bs110@ums.ac.id
}

\begin{abstract}
This research was conducted to determine the effect of annealing and normalizing heat treatment on the results of welding aluminum material similar to AA 5052 on microstructure and properties. In this welding process using a milling machine with a parameter feed rate of $60 \mathrm{~mm} /$ min, tools tilt angle of $3^{\circ}$ and $1500 \mathrm{rpm}$ tool rotation speed. As well as annealing and normalizing performed at $345^{\circ} \mathrm{C}$ with heat retention in the furnace for 2 hours. Mechanical properties are known from tensile testing and hardness testing, physical properties are known from microstructure. The results of this study show that the tensile strength value of raw material is higher than normalizing and annealing with an average stress value of $162.54 \mathrm{MPa}$ and a strain value of $8.61 \%$. The highest hardness value of the base metal area in raw material is $53.7 \mathrm{BHN}$, the $\mathrm{HAZ}$ area and the highest welding value occurs in raw material which is 40.6 BHN and 30.4 BHN. While the lowest hardness value in all areas is in the annealed material. The micro structure in the HAZ region experienced grain growth due to the temperature received during the welding process. The weld nugget shows that the appearance of micro structures are small and tight.
\end{abstract}

Key words: friction stir welding, annealing, normalizing

\section{INTRODUCTION}

In the world of manufacturing industry today we often encounter the manufacture of products or components that require connection of materials, both in the automotive, aviation, shipping and others. Welding is one of the connection methods that is often used for joining materials. In this modern era, many manufacturing industries are developing welding techniques to improve product quality and to reduce production costs. Welding based on the definition of Deutche Industri Normen (DIN) is a metallurgical bond on metal or alloy metal joints which is carried out in a melted or liquid state[1].

The metal welding process can be clarified into two groups, namely: Liquid State Welding (LSW) and Solid State Welding (SSW). LSW is a metal welding process by melting the metal first, whereas SSW is a metal welding process that is carried out under solid conditions or the metal does not reach its melting point when connected. One of the SSW methods is Friction Stir Welding (FSW), which is a welding process that utilizes heat arising from the rotation of the tool rubbing against the parent metal under great axial pressure in the welding area. FSW is a friction welding process that was developed at TWI (The Welding Institute, UK) in 1991[2]. Figure 1 provides an illustration of welding using the FSW method.

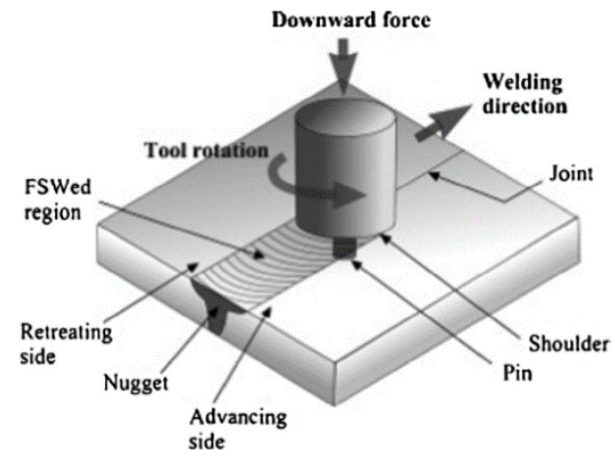

Figure 1: FSW welding process[1].

FSW welding is often applied to aluminum metal or to dissimilar metals. Fsw is often applied to aluminum because aluminum and its alloys are metals that have good formability, relatively high tensile strength, corrosion resistance and mechanical properties can be improved by heat treatment or treatment, and have variable weldability depending on the type of alloy [3]. Weaknesses when the FSW welding process occurs in welding joints that experience softening and a decrease in tensile stress due to the recrystallization process in the nugget zone during the welding process[4], [5]. FSW welding must pay attention to several parameters, such as: toolational speed, welding speed, deep plunge tool, tool's tilt angle to the workpiece, and shape or pin profile. The selection of the right FSW parameters, can produce good connection strength and welding defects can be minimized[6], [7].

In addition to setting the right FSW parameters, there is a further process in the form of heat treatment to obtain better connection results. The heat treatment process is a controlled heating and cooling process, with the aim of changing the physical and mechanical properties of a metal material as desired[8], [9]. The process of heat treatment includes heating, colding, and cooling. The purpose of this study was to determine the effect of heat treatment on aluminum FSW results on tensile strength, hardness, and microstructure. 


\section{RESEARCH METHODOLOGY}

The material used is Al-5052 aluminum alloy with a size of $150 \times 50 \times 3 \mathrm{~mm}$ as many as 6 pieces. After the joining process using the FSW method, the specimen is cut according to ASTM E8 standard as shown in Figure 2, for tensile strength testing. While the stirring pin or chisel used for FSW is made of high speed steel (HSS). The pin is formed in the form of a cylindrical taper with a diameter of 5 $\mathrm{mm}$, taper $3 \mathrm{~mm}$, pin height $2.75 \mathrm{~mm}$, and shoulder diameter $15 \mathrm{~mm}$ as shown in Figure 2.

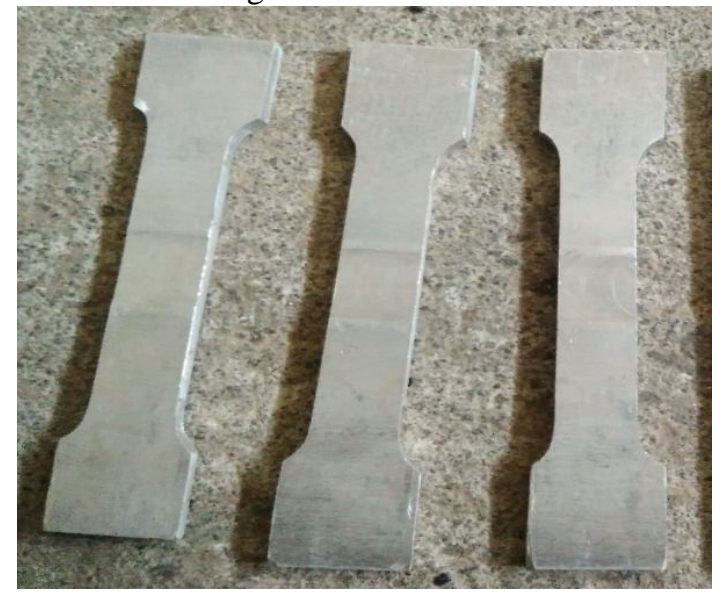

Figure 2: ASTM E8 standard tensile test specimen shape

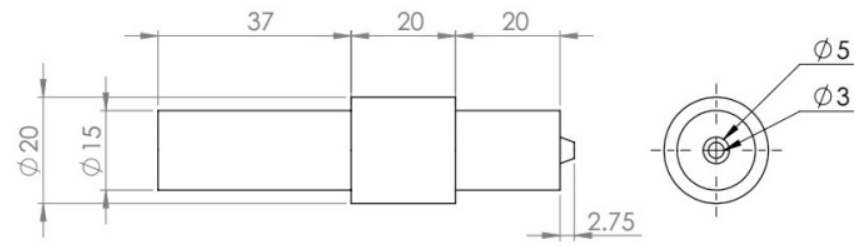

Figure 2: Chisel and pin shapes for FSW (in mm).

The machine used in the FSW process is the universal milling machine Acirea AS-1. While the heating process uses electric furnace. The tool functions to heat the specimen during the annealing and normalizing process. The strength of the FSW Al-5052 connection was tested with the universal testing machine Hung Ta type HT-9501. Material hardness and the results of the connection were tested using the Brevetti "AFFRI" macro vickers machine. The microstructure in the junction area was observed by the Olympus BH 2-VMA microscope. Universal milling machine parameters for the FSW process include $1500 \mathrm{rpm}$ tool speed, $60 \mathrm{~mm} / \mathrm{min}$ feedrate and tilt angel $3^{\circ}$. FSW is done along the $150 \mathrm{~mm}$ side with butt joint type.

The FSW process begins with preparing all the equipment needed such as base metal, tools, backing plates, and milling clamps. The FSW tool is mounted on the gripping shoulder and the base metal is clamped to the milling machine table on the backing plate. The backing plate serves to prevent the base metal from sticking to the milling machine table after the FSW process. The tool is set on the weld line area which is the boundary between two metal bases, so that the rotation and friction between the tool and the metal base will generate heat. The milling machine is run with $1500 \mathrm{rpm}$ tool speed and $60 \mathrm{~mm} /$ minute feedrate.
Penetration tool to base metal as deep as $2.8 \mathrm{~mm}$. Penetration is done manually by raising or lowering the milling machine table to the y axis. The friction stir welding process is carried out after the tool has been held for several minutes to reach a temperature of around $0.8 \mathrm{Tc}$ (melting point) from the base metal. Then the tool is run following the weld line.

The treatment process carried out is annealing and normalizing. The basic principle of annealing is to heat the base metal up to a critical temperature, then holding time is carried out, and the cooling process is carried out in the furnace slowly to reach room temperature. The normalizing process is done by heating the raw material, then holding time with a certain time and cooled in the air freely.

\section{RESULTS AND DISCUSSIONS}

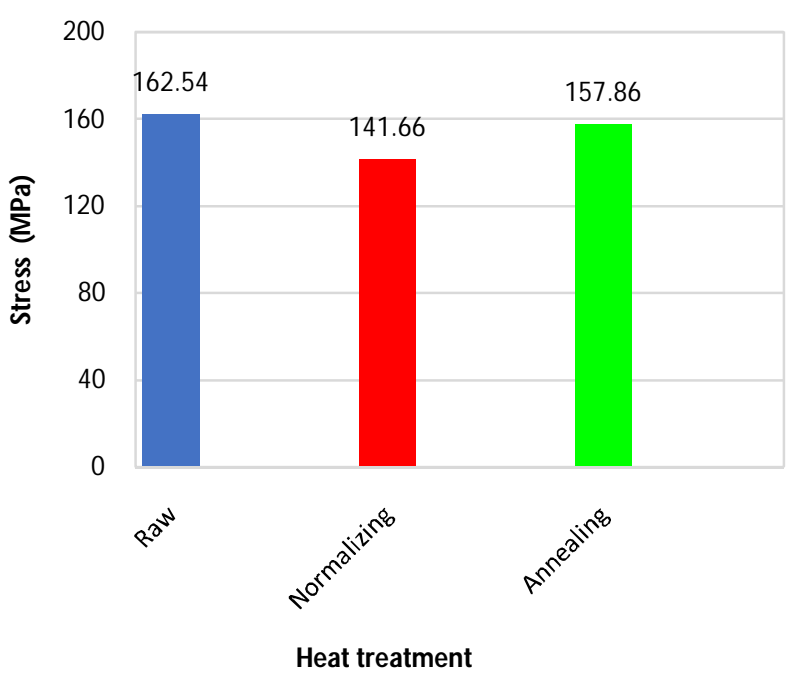

Figure 3: Comparison of Tensile Stress

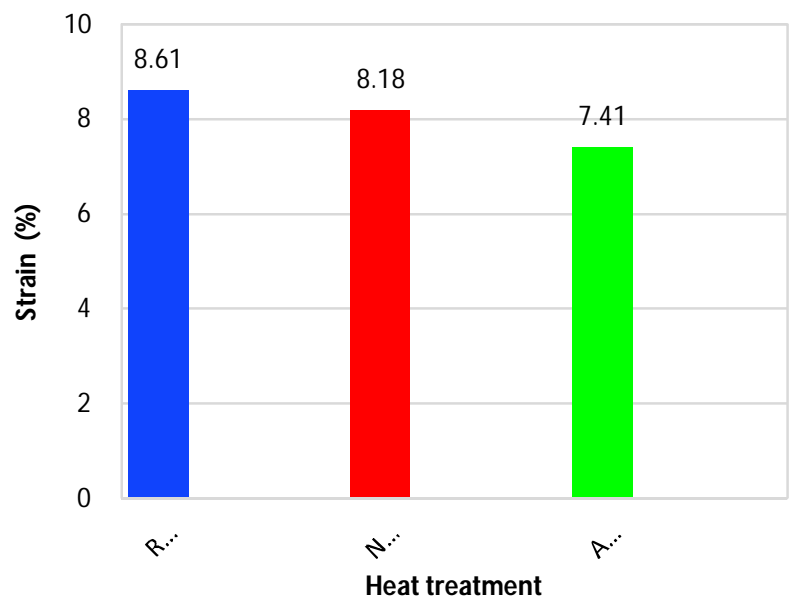

Figure 4: Comparison of Strain Values.

Figure 3 shows the stress histogram of the tensile test results. From Figure 3 it can be said that the tensile stress of 5052 aluminum alloy FSW welding results has a different value. The highest tensile stress is obtained from specimens that are not heat treated. The tensile stress is $162.54 \mathrm{MPa}$. In normalizing specimens the tensile stress of $157.86 \mathrm{MPa}$ was 
obtained. This happened because the aluminum alloy 5052 series included non-heat treatable aluminum alloys[10]. The results of the tensile test fracture occur in the weld nugget area with a fault shape perpendicular to the direction of loading.

Figure 4 shows the tensile strain histogram of the FSW Al-5052 results. From Figure 4, it can be seen that the largest strain value is obtained from specimens that are not heat treated. The strain obtained was $8.61 \%$. In specimens carried out normalizing heat treatment, a strain of $8.18 \%$ was obtained. In the annealing specimen, a $7.41 \%$ strain was obtained. The lowest strain was obtained from the annealing specimen compared to the others. This happens because the aluminum alloy 5052 series includes non-heat treatable aluminum alloys.

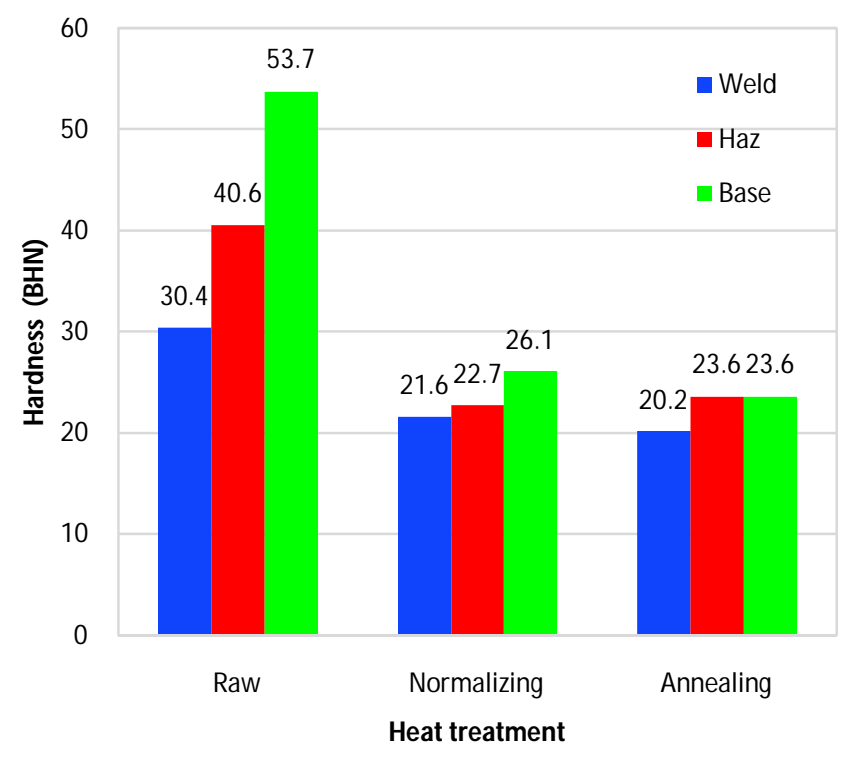

Figure 6: Comparison of Hardness Value Results

From the histogram above, it shows that the coverage value on each heat discussion variable or without heat calculation on the welding results of the Aluminum Alloy 5052 Stirring Friction (FSW) has a higher hardness value in each of the test fields as shown in Figure 6. The exchange rate for the base area namely the raw material of 53.7 BHN. While the lowest average value is annealing that is equal to 23.6 BHN. The highest average value for raw materials is 40.6 BHN, while the lowest average value is normalization of 22.7 BHN. Then for the highest average value of raw materials, that is $30.4 \mathrm{BHN}$, while the lowest average added value of welds is $20.2 \mathrm{BHN}$.

The value of the average hardness of the results of the Friction Stir Welding (FSW) carried out by heat treatment decreased the hardness value compared to raw material, because the Al-Mg alloy material which has undergone heat treatment has undergone a diffusion process namely have experienced molecular movements in materials and this process is expected to result in uniform or homogeneous composition, while magnesium $(\mathrm{Mg})$ is still in the form of clustered granules in this case because magnesium $(\mathrm{Mg})$ is a non-heat treatable material group material that cannot be hardened by the heat treatment process [7].
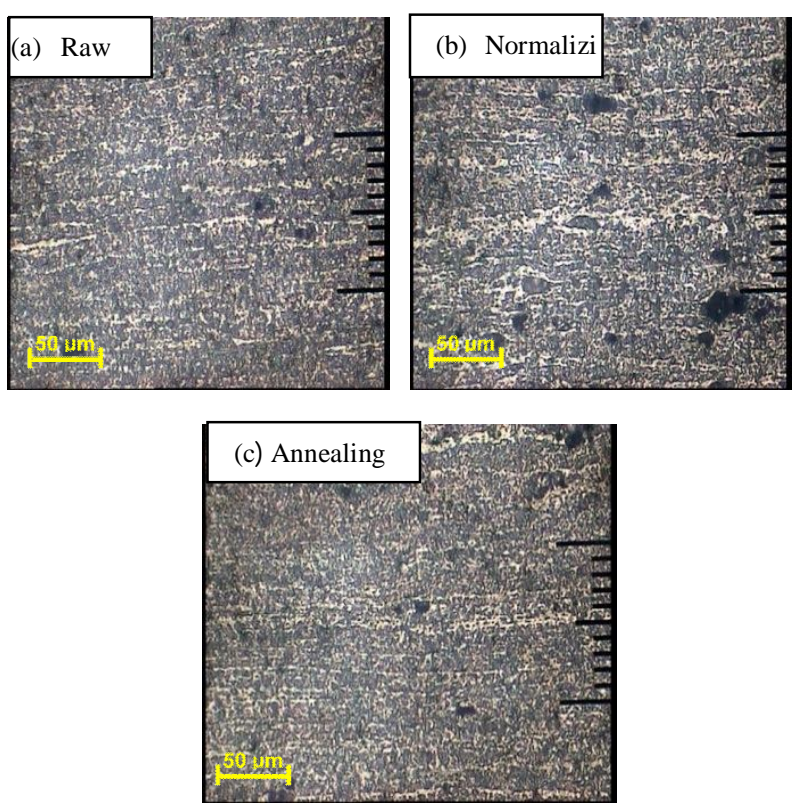

Figure 7: Microstructure of base metal area (a) Raw, (b) Normalizing, (c) Annealing with magnification 200 times.
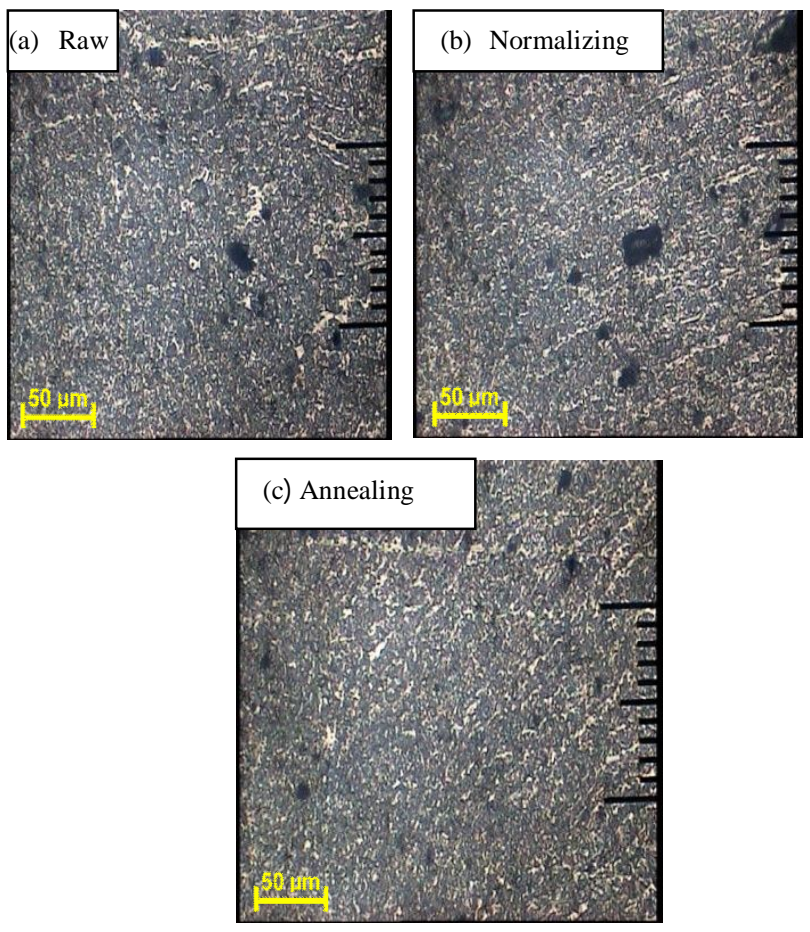

Figure 8: Microstructure of the HAZ region (a) Raw, (b) Normalizing,(c) Annealing with magnification 200 times. 

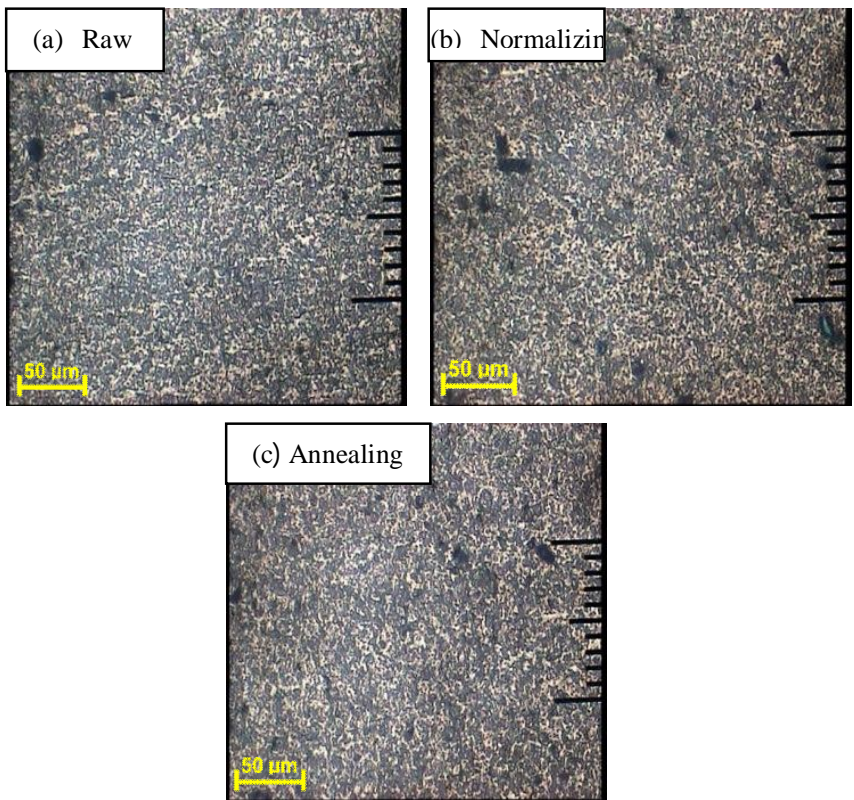

Figure 9: Microstructure of the Las area (a) Raw, (b) Normalizing, (c) Annealing

From pictures 7,8 and 9 can be seen the micro structure of the results of welding Friction Stir Welding (FSW) which does not undergo heat treatment and heat treatment in the form of annealing and normalizing in the base metal, HAZ and welding areas which is displayed in two phases, namely aluminum solid solution which is shown in white and $\mathrm{Mg}$ phase which is shown in black. The $\mathrm{Mg}$ content greatly influences the mechanical properties of aluminum[11].

The micro structure of the base metal region shown in Figure $7 \mathrm{a}$, is an area that is not affected by welding either hot or mortar, so the material is not deformed. In the micro photo it is displayed in two phases, namely the aluminum phase which is shown in white and the magnesium phase $(\mathrm{Mg})$ which is shown in black. Micro base metal structure that has small to medium granules (figure 7) is in raw material. Whereas those that have large and coarse grains are normalizing in the heat treatment area (Figure $7 \mathrm{~b}$ ), due to the rapid cooling process at room temperature, so that the structure does not have enough time to change. And those that have small and fine grain structures are areas that are treated for annealing (Figure 7c), because the longer cooling is inside the furnace, so the structure has a chance to change[6][13-15].

In the micro structure, the HAZ region is an area that experiences a thermal cycle but does not undergo plastic deformation. In this area also changes the microstructure. HAZ region changes in grain size (grain size) where the change in size depends on the material characteristics, temperature, heating time and cooling rate. Micro structure in the HAZ area that is not heat treated, raw, normalizing, annealing is seen more grain size changes but is not mechanically deformed because of the friction stir welding process as shown in Figure 8.

In the weld nugget area shown in Figure 97, grain refinement occurs, meaning that the area undergoes plastic deformation and heating during the Friction Stir Welding
(FSW) process so as to produce fine grains in the stirring area. From the observations of the three welding area variables that were not heat treated (raw) and the welding area which was treated with normalizing heat and granular annealing did not change much, this was due to $\mathrm{Al}-\mathrm{Mg}$ aluminum alloy material including aluminum alloy material which could not accept heat treatment (non heat treable)[12].

\section{CONCLUSION}

Welding of FSW Aluminum Alloy 5052, obtained a smooth surface contour and there is a weld flash caused by stirring shoulders and pins during the welding process. Tensile test data shows that the welding of FSW without heat treatment (raw) has the highest tensile stress value of $162.54 \mathrm{MPa}$ and the highest strain value of $8.61 \%$. The normalizing heat treatment material has the lowest tensile stress value of 141.66 MPa and strain value of $8.18 \%$. And in Annealing material, the tensile stress value is $157.86 \mathrm{MPa}$ and the lowest strain value is $7.41 \%$. From the tensile test data, that the heat treatment of Aluminum Alloy 5052 material is able to change the tensile and strain stress values of the material.Hardness testing in the Weld Nugget area obtained the highest hardness value in raw material of 30.4 BHN. In the HAZ area, the highest hardness value obtained in Raw material was $40.6 \mathrm{BHN}$. And in the base metal area the highest hardness value obtained in Raw material is 53.7 BHN. The FSW welding process affects the value of violence in the Weld Nugget area where the area is the area where the fault occurs when tensile tested and heat treatment causes a decrease in the value of hardness compared to raw material. The heat treatment affects the grain shape of the AA-5052 material, but it does not change much due to the $\mathrm{Mg}$ alloy properties of the AA-5052 material which has nonheat-treatable properties.

\section{REFERENCES}

1. X. He, F. Gu, and A. Ball, "A review of numerical analysis of friction stir welding," Prog. Mater. Sci., vol. 65, pp. 1-66, 2014.

2. W. M. Thomas, E. D. Nicholas, J. C. Need ham, M. G. Murch, P. Templesmith, and C. J. Dawes, "Friction stir butt welding," Int. Pat. Appl. no. PCT/GB92/02203 GB Pat. Appl. no. 9125978.8, no. 6 December 1991, 1991.

3. B. Li, Z. Zhang, Y. Shen, W. Hu, and L. Luo, "Dissimilar friction stir welding of Ti-6Al-4V alloy and aluminum alloy employing a modified butt joint configuration: Influences of process variables on the weld interfaces and tensile properties," Mater. Des., vol. 53, pp. 838-848, 2014.

4. A. D. Anggono, B. Sugito, A. Hariyanto, Subroto, and Sarjito, "Mechanical Behaviour Investigation Of Aluminium Alloy Tailor Welded Blank Developed By Using Friction Stir Welding Technique," J. Phys. Conf. Ser. Pap., pp. 2-11, 2017.

5. A. D. Anggono, T. Widodo, B. Riyadi, D. Triyoko, and A. Hariyanto, "Influence of Tool Rotation and Welding Speed on The Friction Stir Welding of AA 1100 and AA 6061-T6," AIP Conf. Proc., vol. 020054, 2018. 
6. J. Zhang, Y. Shen, X. Yao, H. Xu, and B. Li, "Investigation on dissimilar underwater friction stir lap welding of 6061-T6 aluminum alloy to pure copper," Mater. Des., vol. 64, no. July, pp. 74-80, 2014.

7. W. Y. Li et al., "Effects of tool rotational and welding speed on microstructure and mechanical properties of bobbin-tool friction-stir welded Mg AZ31," Mater. Des., vol. 64, pp. 714-720, 2014.

8. P. Kannan, K. Balamurugan, and K. Thirunavukkarasu, "An experimental study on the effect of silver interlayer on dissimilar friction welds 6061-T6 aluminum MMC and AISI 304 stainless steel," Indian J. Eng. Mater. Sci., vol. 21, no. December, pp. 635646, 2014.

9. X. Liu, S. Lan, and J. Ni, "Analysis of process parameters effects on friction stir welding of dissimilar aluminum alloy to advanced high strength steel," Mater. Des., vol. 59, pp. 50-62, 2014.

10. S. Y. Tarasov, V. E. Rubtsov, and E. A. Kolubaev, "A proposed diffusion-controlled wear mechanism of alloy steel friction stir welding (FSW) tools used on an aluminum alloy," Wear, vol. 318, no. 1-2, pp. 130134, 2014
11. P. Pourahmad and M. Abbasi, "Materials flow and phase transformation in friction stir welding of $\mathrm{Al}$ 6013/Mg," Trans. Nonferrous Met. Soc. China (English Ed., vol. 23, no. 5, pp. 1253-1261, 2013.

12. R. I. Rodriguez, J. B. Jordon, P. G. Allison, T. Rushing, and L. Garcia, "Materials \& Design Microstructure and mechanical properties of dissimilar friction stir welding of 6061-to-7050 aluminum alloys,” J. Mater., vol. 83, pp. 60-65, 2015.

13. E. Julianto, W. A. Siswanto, and M. Effendy, "Characteristics of Temperature changes and Stress of Float Glass," Int. J. Emerg. Trends Eng. Res., vol. 7, no. 9, pp. 228-233, 2019.

14. A. D. Anggono, N. Ernawan, and T. W. B. Riyadi, "Analysis of mechanical and metallographic properties on the joining between aluminum and brass by using the brazing method," Int. J. Emerg. Trends Eng. Res., vol. 8, no. 2, pp. 440-446, 2020.

15. A.S. Darmawan, W.A. Siswanto, T. Sujitno, "Comparison of commercially pure titanium surface hardness improvement by plasma nitrocarburizing and ion implantation”, Advanced Mater. Res., 789, pp. 347351, 2013. 